\title{
LOSS OF SIGHT FOLLOWING SNAKE BITE*
}

\author{
BY
}

\author{
R. C. DAVENPORT AND F. H. BUDDEN \\ London, and the Colonial Medical Service, Nigeria
}

Loss of sight following haemorrhage is a long established clinical entity, but its pathology and the causation of the optic atrophy are still uncertain. The following case, to which we have been able to find no parallel in the literature, shows an unusual cause of bleeding leading to loss of sight.

\section{Case Report}

Notes of Original Lesion. + -A European male, aged 51, was admitted to hospital at 7 p.m. on February 11, 1952, within half an hour of being bitten by a viperine snake on the dorsum of the left foot (specimen identified as Echis carinatus). He was treated immediately by tourniquet and incisions of the bitten area under pentothal; $10 \mathrm{ml}$. antivenine were injected locally and $10 \mathrm{ml}$. intramuscularly.

February 12, his general condition was good, but the incisions started oozing blood and continued to do so, despite styptics and pressure dressings.

February 13, the systolic blood pressure fell to $85 \mathrm{~mm}$. $\mathrm{Hg}$, and the erythrocytes to 2.5 million, necessitating immediate blood transfusion $(450 \mathrm{ml}$.) with marked benefit.

February 14 and 15, slight oozing only of wounds and mucous membranes of mouth, but extensive extravasation of blood into muscles of thigh and buttocks at sites of penicillin injections and application of tourniquet. The oozing from the incisions was well controlled and there were no local or general signs of sepsis and no leucocytosis. On these two days the haemoglobin figures were 60 per cent. and 65 per cent.

February 17, general condition very poor with the blood pressure 85 systolic. For the first time he complained of lower field blindness of the right eye. A second blood transfusion $(500 \mathrm{ml}$.) started at 12 noon raised the systolic blood pressure to 120 , and his general condition improved.

February 18 , no change occurred in the vision of the right eye.

February 19, In the morning he complained of "blind spots" in the temporal field of the left eye.

February 20, both pupils reacted to light but the left pupil was a little larger than the right. No perception of light was present in the lower right visual field; there were no obvious changes in the disks. The haemoglobin was 65 per cent. and a further blood transfusion of $500 \mathrm{ml}$. was given.

February 21 , the left eye was worse subjectively and the pupil a little larger than before but still reacting to light though dilating almost at once.

February 22, there was no perception of light in the left eye and the pupil response was negligible.

February 23, haemoglobin $75-80$ per cent. and the blood pressure 120 systolic; the patient's general condition was excellent.

* Received for publication October 13, 1952.

+ Kindly supplied by Dr. D. W. McLaren, Medical Officer in Charge, Kaduma Area, Nigeria. 
Ophthalmic Findings (F.H.B.). February 28, 1952

Right eye-6/6 with correction. Loss of lower half of visual field; the patient describes the line of demarcation as quite sharp and as passing through the middle of any object at which he looks (e.g., print in a book); pupil reacts normally to light and accommodation; fundus-disk edges blurred both above and below, all veins distended, especially on and near the disk; retinal oedema around disk; no haemorrhages or exudates seen.

Left eye-no perception of light; pupil-no direct reaction to light but consensual reaction normal; fundus-disk swollen and edges blurred, especially above and below; veins distended; small haemorrhages at and near the disk margin, retinal oedema making the fovea stand out red; pinpoint exudates to the temporal side of the disk and over the macular region.

Ophthalmic Findings (R.C.D.). April 7, 1952

Right eye-6/5 with correction; sharp horizontal demarcation of visual field with all the lower half lost; direct pupil reactions brisk; media clear; optic disk clear cut and pale generally but all blood vessels quite normal in appearance.

Left eye-bare perception of light in all directions, best in upper temporal quadrant; no direct pupil reaction; sharply defined, very pale disk with arterial branching grossly attenuated.

Both fundi otherwise normal.

\section{Discussion}

Echis carinatus is a true viper of particularly malignant type found in hot desert surroundings, e.g., Kaduna. Recent papers by French medical officers (Giboin, 1951; Salou, 1951) suggest that Echis carinatus in Africa is larger and even more deadly than the Indian variety (Purohit, 1944) and that its bite is almost invariably fatal. Prompt sustained efficient treatment saved this patient's life, and this fact, with the severity of the bite, provided the unique clinical picture. Echis venom contains in addition to anticoagulants and haemolysins much haemorrhagin, and death after a bite is usually due to multiple haemorrhages and/or possibly depression of the vaso-motor centre. It may occur from 1 to 5 or more days after the bite. The only neurotoxic effect is on the vaso-motor centre. It seems quite unequivocal that the loss of sight in this case was related to the actual bite, and therefore to the bleeding which the venom caused. The only other possible element was that the patient was given four tablets each of $0.20 \mathrm{~g}$. "Nivaquine" brand chloroquin sulphate, as in the course of blood examination two doubtful malaria parasites were found. We can find no evidence of this drug producing amblyopia even when given in very much larger dosage, and we cannot think it played any part in the sequence of events.

The case history follows the usual pattern, for the amblyopia did not immediately follow the repeated bleeding, one eye losing sight on the sixth day after the bite, and the other on the eighth day. At no stage was a very low haemoglobin level found, though low systolic blood pressure readings preceded the blindness. Further, total blindness did not result, the retained field being as usual the upper. Even in the left eye, such perception of light as remained was more definite in the upper field. 
The interpretation seems to us to be that of retinal arterial spasm affecting first the right eye, and presumably lasting long enough only in the upper branches of the artery for complete death of the ganglion cells. The passing of the spasm allowed refill to normal appearance of the whole arterial tree, although the general pallor of the disk must mean some atrophy over all the inner retina. The spasm in the left eye was of such intensity as to produce total optic atrophy and permanent narrowing of the vessel. The appearance of oedema subsequent to the loss of sight has been frequently described and may be explained by damage to the capillary endothelium due either to the actual lowered blood supply, or as in capillaries elsewhere to the direct effect of the snake venom. The whole picture fits in well with the explanations of the course of events given by Wolff (1935) but provides no clearer reason for the selective severity of damage to the upper retina than his suggested explanation of gravity. Certainly this patient was nursed for the most part with the head partly raised.

The literature consulted (Lewin and Guillery, 1905; Phisalix, 1922) contains some generalizations on loss of sight following snake bite and amaurosis before death is mentioned, but as stated above we have been unable to trace any report of a case similar to this one. The only other remotely related case was that of a man admitted to Moorfields Eye Hospital with amblyopia which he attributed to the effects of a snake bite. In this case there was no proof of the viperine nature of the snake, no history of haemorrhage, and no pathological findings. Diagnosis of an ocular psychoneurosis was borne out by the complete recovery which resulted, and the history did not even suggest that the psycho-neurosis was based on any physical lesion due to the snake bite, the effects of which had passed quickly before the case came under observation.

We wish to thank Dr. S. L. A. Manuwa, Director of Medical Services, Nigeria, for permission to publish the case, and Dr. C. J. Hackett, Director of the Wellcome Museum of Medical Science, and Dr. R. B. Hawes of the Colonial Office for help and advice about snake bite and the effects of venom.

\section{REFERENCES}

Giborn, L. M. (1951). Med. trop., 11, 661.

Lewin, L., and Guillery, H. (1905). "Die Wirkungen von Arzneimitteln und Giften auf das Auge ", vol 1, p. 836. Hirschwald, Berlin.

Phisalix, M. (1922). “Animaux Venimeux et Venins”, vol. 2, p. 559. Masson, Paris.

Purohit, G. R. (1944). Indian med. Gaz., 79, 266.

Salou, G. (1951). Med. trop., 11, 655.

WolfF, E. (1935). Trans. ophthal. Soc. U.K., 55, 342. 